\title{
Restoratif İşlemlerdeki Hasta Memnuniyetinin Belirlenmesi Üzerine Bir Pilot Çalışma
}

\author{
A Pilot Study on Determination of Patient Satisfaction in Restorative Procedures
}

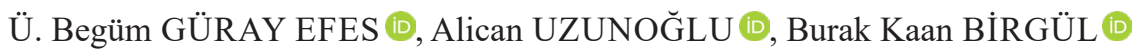

Öz

Amaç: Hastaların, aldıkları diş hekimliği hizmetlerine yönelik beklentilerini belirlemek, tedavi hizmetlerinde diş hekimi ve sağlık çalışanlarının hastalar ile olan ilişkisini gözlemlemek, diş hekimliği tedavilerindeki memnuniyeti geliştirmeye yönelik hastalardan bilgi alımını sağlamak amaçlanmıştır. Diş hekimliği hizmeti veren bireylerin, tedavi sırasında hastaların uygulama etaplarındaki memnuniyetini etkileyen faktörleri belirleyerek bu veriler 1şığında hekimlere ve diğer sağlık çalışanlarına, hizmet verdikleri bireylere yönelik veri elde edilmesi amaçlanmıştır.

Gereç ve Yöntem: İstanbul Üniversitesi Diş Hekimliği Fakültesi'nde restoratif diş tedavisi gören hastalara anket formları verilerek cevaplanması istenmiştir. Restoratif işlemin, İstanbul Üniversitesi Diş Hekimliği Fakültesi'nde eğitim gören diş hekimliği öğrencileri tarafından tamamlanmasının ardından 250 hastadan form doldurması istenmiştir. Anket sonucundaki kriterlerin karşılaştırılmasında Ki-Kare yöntemi ve SPSS programı kullanılmıştır.

Bulgular: Çalışmamızda yaptığımız anketlerin sonuçlarına göre tedavi sırasında hissedilen acı $(\mathrm{p}=0.005)$, hastanın tedavi sırasındaki oturma pozisyonu $(\mathrm{p}=0.047)$ ve tükürük emicinin kullanımı $(\mathrm{p}=0.014)$ kriterlerinin hasta memnuniyetini etkileyen faktörler arasında istatistiksel olarak anlamlı fark olduğu gözlenmiştir.

Sonuç: Restoratif tedavi sırasında kullanılan tükürük emicinin çevre yumuşak dokulara olan baskısı ve dentin hassasiyetine sebep olmas1, hasta pozisyonunun ideal ergonomik konumda ayarlanamaması, tedavi esnasında oluşan ağrı hissinin kontrol edilememesi hasta memnuniyetinin derecesinin düşük olmasına sebep olmaktadır. $\mathrm{Bu}$ da hastaların bir sonraki seanslara gelmemesine ve hekim ile ilişkilerini kesmelerine sebep olmaktadır.

Burak Kaan BİRGÜL(匈)

İstanbul Üniversitesi, Diş Hekimliği Fakültesi, Restoratif Dişs Tedavisi Anabilim Dall

e-mail:bkbirgul@gmail.com

Ü. Begüm GÜRAY EFES

Istanbul Üniversitesi, Diş Hekimliği Fakültesi, Restoratif Diş Tedavisi Anabilim Dalı

Alican UZUNOĞLU

Serbest Diş Hekimi

Submitted / Gönderilme: 12.08.2019

Accepted / Kabul:29.06.2020
Bunun sonucu olarak basit tedavi prosedürleri ile çözülebilecek olan işlemler hastalığın ilerlemesine bağlı olarak komplike hale gelmekte ve bu da hem hastayı hem de ülke ekonomisini zarara uğratan bir süreç olarak karşımıza çıkmaktadır.

Anahtar Kelimeler: Dental restorasyonlar, diş hekimliği hizmetleri, hasta memnuniyeti

\section{Abstract}

Objective: The aim of this study is to determine the expectations of the patients for the dental services they receive, to observe the relationship between the dentists and health workers in the treatment services and to obtain information from the patients in order to improve the satisfaction of the dental treatments. The aim of this study was to determine the factors that affect the satisfaction of the patients who provide dental services during the application stages of the patients during the treatment and to obtain data for physicians and other health workers and the individuals they serve.

Materials and Methods: Questionnaires were given to the patients receiving restorative dental treatment at Istanbul University Faculty of Dentistry. After the restorative procedure was completed by dental students studying at the Faculty of Dentistry of Istanbul University, 250 patients were asked to fill in the form. Chi-square method and SPSS program were used to compare the criteria at the end of the survey.

Results: According to the results of the questionnaires we conducted in our study, it was observed that there were statistically significant differences between the factors that affected patient satisfaction during the treatment $(\mathrm{p}=0.005)$, sitting position during treatment $(\mathrm{p}=0.047)$ and use of saliva ejector $(\mathrm{p}=0.014)$.

Conclusion: The saliva ejector used during restorative treatment causes pressure on the surrounding soft tissues and dentin sensitivity, the patient position cannot be adjusted to the ideal ergonomic position, and the feeling of pain cannot be controlled during the treatment leads to low patient satisfaction. This causes the patients not to come to the next sessions and to cut off their relations with the physician. As a result, the procedures that can be solved by simple treatment procedures become complicated depending on the progression of the disease and this is a process that harms both the patient and the national economy.

Keywords: Dental restorations, dental services, patient satisfaction 


\section{GİRiş}

Yirminci yüzyılda teknolojik gelişmelerle birlikte bilim, tüm çağlar boyu yaşadığı en hızlı değişimi gösterdi. Gelişen teknolojik gelişmelerle birlikte insanların yaşam kalitesi ve beklentileri de doğru orantılı olarak arttı (1). Zaman içerisinde hastalar, sadece tedaviye yönelik uygulamaların kalitesine değil aynı zamanda verilen hizmete yönelik kalite arayışına girmişlerdir (2-4). Bu da sağlık kuruluşlarının eski klasik yöntem anlayışlarını değiştirmelerine yol açmış, kaliteli bir hizmet verebilmek için hasta odaklı iletişim ve memnuniyet kavramlarının merkezde alındığ 1 bir anlayış benimsenmiştir. Sağlık hizmetlerinin, hasta memnuniyeti dikkate alınmadan yüksek kalitede tedavi hizmeti verilemeyeceği yönünde ortak bir görüş geliştirilmiştir (5$6)$.

Hasta memnuniyeti, değişkene bağlı olan çok faktörlü bir kavram olarak karşımıza çıkmaktadır. Bu faktörler arasında hastanın eğitim geçmişi, yaşam tarzı, önceki tıbbi deneyim ve beklentileri vs. gibi birçok değişken bulunmaktadır $(9,10)$. Yapılan çalışmaların sonucunda 'Hasta memnuniyeti, verilen hizmetin hastanın beklentilerini karşılaması ya da hastanın verilen hizmeti nasıl algıladığına dayanmaktadır.' şeklinde genel bir kabul bulunmaktadır $(2,9)$. Buradan hareketle literatürde hasta memnuniyetinin temelini hasta beklentileri ve geniş ölçüde hasta hekim birlikteliğinin oluşturduğu vurgulanmaktadır (10-12). Bir başka tanıma göre 'Hasta memnuniyeti, hastanın sağlık hizmeti alma kararından itibaren bu hizmeti araştırması, bulması, hizmete ulaşması ve kullanması vb. süreçlerde yaşadığı olaylar ve elde ettiği faydalar ile beklentilerinin karşılaştırılması sonucu ulaştığı tatmini düzeyidir $(9,13)$.'

Memnuniyetin belirlenmesinde, anket formları önemli bir araç olarak karşımıza çıkmaktadır. Genel anlamda, araştırmalarda öne çıkan anketlere baktığımızda; Corah'ın Dental Visit Satisfaction Scale (DVSS) ve Dental Anxiety Scale (DAS) karşımıza çıkmaktadır. DVSS ve DAS, kişilerin normal günlük hayatlarında veya karşılaştıkları farklı durumlarda sahip oldukları anksiyetenin belirlenmesi amaciyla kullanılan sorgulama testleri olarak karşımıza çıkmaktadır $(14,15)$. Başka bir anket çalışması olarak SERVQUAL anketi, tedavi hizmetlerinden hasta memnuniyetini değerlendiren ticari bir anket olarak kullanılmaktadır (13).

Son yıllarda ülkemizdeki sağlı sistemi, hizmetteki kalite ve hasta odaklı hale gelmiştir (3). Bu yapıda belirleyici bir unsur olarak hekimlerin hastalarla olan iletişim becerileri önem kazanmıştır. İletişim becerisi hekimlerin ve sağl1k kuruluşlarının tercih edilebilirliğini etkileyen en önemli faktör olarak karşımıza çıkmaktadır (5). Hastaların beklentileri sağlık hizmetlerinin en önemli çıktılarından biri olarak, hizmet sürecinde ve kalite çalışmalarında üzerinde önemle durulan bir konudur $(4,12,16)$.

Hastaların, diş hekimliği hizmetlerine yönelik memnuniyetini etkileyen faktörleri belirlemek ve diş hekimliği tedavilerindeki memnuniyeti geliştirmeye yönelik hastalardan bilgi alımını sağlamak amaçlanmıştır. Diş hekimliği hizmeti veren bireylerin; tedavi sırasında, hastaların uygulama etaplarından duydukları memnuniyet ve konfora yönelik veri elde etmek istenmiştir. Yapılan çalışma ile bu veriler ışığında hekimlere ve diğer sağlık çalışanlarına, hizmet verdikleri bireylere yönelik yapıcı davranış tarzını hatırlatmak ve bunun öneminin altını çizmek ile birlikte tedavi sırasındaki olumsuz faktörlerin belirlenip tedavinin sürdürülebilirliğine katk1 sağlamak amaçlanmaktadır.

\section{YÖNTEM}

Çalışmaya katılacak bireyler İstanbul Üniversitesi Diş Hekimliği Fakültesi Diş Hastalıkları ve Tedavisi Anabilim Dalı'na çalışma için belirlenen iki aylık süreçte araştırma kriterlerine uygun olmak koşulu ile rastgele seçilmiştir. Katılımcıların: Dişlerinin birinde yada birden fazlasında pulpa dokusuna ulaşmayan çürük bulunması, on sekiz ile altmış beş yaş arasında olması, ciddi bir sistemik hastalığının bulunmaması, restorasyon bölgesinde yanıltıcı bir ağrının kaynağı olabilecek herhangi bir enfeksiyon odağı çürük yada gözlenebilen herhangi bir hastalığının olmaması istenmiştir.

Katılımcılar: Restorasyon öncesinde geçmeyen şiddetli ağrılar ve gece zonklama şeklinde oluşan ağrılarının var olmas1, hamilelik ya da emzirme sürecinde olması, beslenme bozuklukları olması, ciddi sistemik hastalıkların bulunması, aşırı bir diyet uygulaması ve şiddetli asitlere maruz kalması, üç ay içerisinde periodontal cerrahi operasyon geçirmiş olması durumunda araştırmaya dahil edilmemiştir.

Araştırma grubunun belirlenmesi işlemi öncesi hastalar, çalışma hakkında yazılı ve sözlü onayları alınmıştır. İstanbul Üniversitesi Diş Hekimliği Fakültesi'nde restoratif diş tedavisi gören hastalara anket formları verilerek cevaplanması istenmiştir.

Restoratif işlemin İstanbul Üniversitesi Diş Hekimliği Fakültesi'nde eğitim gören diş hekimliği öğrencileri 
tarafindan; tedavinin tamamlanmasının ardından hastaya, form doldurtulmuştur.

Hasta memnuniyetini belirlemek için sorulan 15 soruya verilen toplam puan $45^{\prime}$ in altinda olmasi durumunda memnuniyet derecesi düşük, üzerinde olması durumunda memnuniyet derecesi yüksek olarak kabul edilmiştir

\section{Araştırma Kurgusu için Gerekli Minimum Denek Sayısının Saptanması}

Çalışmada 'Restoratif İşlemlerdeki Hasta Memnuniyetinin Belirlenmesi' konulu çalışmada anket uygulanacağı denek sayısının çok değişkenli çözümlemelerde teorik olarak yeterliliği kabul edilen 1/10 oranı dikkate alındığında, toplam 25 soruluk anket için 250 denek kullanılması, yapılacak ileri analizler, çok değişkenli çözümlemeler ve diğer bivarite hesaplama kurguları için gerekli minimum denek sayısı olarak kabul edilmiştir.

Çalışmanın istatistiksel olarak çözümlemesinde, ele alınan primer ölçüte ait sıklıklar frekans ve yüzde değerleri ile tanımlanmıştır. Gruplar arası frekans ve yüzdelerin kıyaslanmasında Ki-kare kesin olasılık testi kullanılmıştır. Yorumlamalarda anlamlılık sınırı $\mathrm{p}=0.05$ alınmıştır. Çalışmamızdaki istatistiksel analizlerde SPSS (Sürüm:22) paket programı kullanılmıştır.

\section{BULGULAR}

Hastalar, hekimin tedavi konusunda sunduğu seçeneklerden memnun olma konusunda 250 hastanın 240'1 olumlu bildirimde bulunmuştur [Tablo 1]. Hekimin tedavi sırasındaki hastaya karşı davranışları yönünden değerlendirilmesinde 250 hastanın 217'si olumlu bildirimde bulunmuştur [Tablo 2]. Hekimin, tedavi sirasında hastaya vermiş olduğu güven yönünden değerlendirilmesinde 250 hastanın 234'ü olumlu bildirimde bulunmuştur [Tablo 3]. Restoratif diş tedavisi kliniğinde diş çürüğü tedavisinde kullanılan malzemelerin kalitesine yönelik değerlendirmede 233 hasta olumlu bildirimde bulunmuştur [Tablo 4]. Hastalara yönelik koruyucu hekimliğin önemi konusunda 250 hastanın 201'i katıldığını bildirmiştir [Tablo 5]. 250 hastanın genel değerlendirme formu kapsamında 15 soruya verdikleri puanlara göre 196 hasta yapılan tedaviyle ilgili olumlu bildirimde bulunmuştur [Tablo 6]. \% 21,6’llk kısımda bulunan hastaların memnuniyet derecesinin düşük olmasının nedeninin tespit edilebilmesi için tedavi sırasındaki faktörler değerlendirilmiştir. Bu sonuçlara göre tükürük emiciden rahatsız olan hasta sayısı 154 iken, 96 hasta etkilenmemiş̧ir. Reflektör 1şı̆̆ından rahatsız olan hasta sayıs1 46 iken, 204 hasta etkilenmemiştir. Kliniğin ortamindan rahatsız olan hasta sayısı 24 iken, 226 hasta etkilenmemiştir. Kullanılan pamuktan rahatsız olan hasta sayısı 39 iken, 211 hasta etkilenmemiştir. Tedavi sırasındaki oturma pozisyonundan rahatsız olan hasta sayısı 108 iken, 142 hasta etkilenmemiştir. Kliniğin fiziki koşullarından rahatsız olan hasta sayısı 31 iken, 219 hasta etkilenmemiştir. Malzemelerin kalitesinden rahatsız olan hasta sayısı 13 iken, 237 hasta etkilenmemiştir. Materyallerin temizliğinden rahatsız olan hasta sayıs1 18 iken, 232 hasta etkilenmemiştir. Acı hissetmesinden kaynaklı rahatsız olan hasta sayısı 176 iken, 74 hasta etkilenmemiştir[Tablo 7]. Tedaviaşamasındaki etkenler ile hasta memnuniyeti arasındaki ilişki istatistiksel olarak kıyaslandığında hastaya yöneltilen 10 tane faktörden tükürük emici ( $\mathrm{p}=0.014)$, oturma pozisyonu $(\mathrm{p}=0.047)$, tedavi sirasındaki acı $(\mathrm{p}=0.005)$ memnuniyeti istatistiksel olarak anlamlı düzeyde etkileyen faktörler olarak ortaya çıkmıştır. Tedavi aşamasındaki etkenlerden hasta memnuniyetini etkileyen en önemli faktör olarak tedavi sırasında hissedilen ac1, hastaların memnuniyetsizliğine \% 70.4 oranında en çok sebep olan faktör olarak karşımıza çıkmıştır. Tedavi sırasında hissedilen acı faktörünü takiben, $\% 61.6$ oranında tükürük emici ve $\% 43.2$ oranında oturma pozisyonu, hasta memnuniyetinin derecesinin düşmesine sebep olan diğer faktörler olarak görülmektedir. Katılımcıların 182'si kadın hastalardan oluşurken, 68'i erkek hastadan oluşmaktadır. Katılımcıların \% 26,4'ü 18-29 yaş; \% 18,8'i 30-39 yaş; \% 30'u 40-49 yaş; \% 24,8'i 50-59 yaş arasındadır [Tablo 8].

Tablo 1: Hekimimin Diş Çürüğümün Tedavisi İçin Sunduğu Seçeneklerden Memnunum

\begin{tabular}{|l|l|l|}
\hline TABLO 1 & Say1 & Oran (\%) \\
\hline Tamamen Katıliyorum & 231 & 92,4 \\
\hline Kısmen Katıllyorum & 9 & 3,6 \\
\hline Kararsızım/Bilmiyorum & 4 & 1,6 \\
\hline Çok Az Katılyyorum & 5 & 2 \\
\hline Hiç Katılmıyorum & 1 & 0,4 \\
\hline Toplam & 250 & 100 \\
\hline
\end{tabular}

Tablo 2: Hekimimin Titiz Davranışından ve Ciddiyetinden Memnunum

\begin{tabular}{|l|l|l|}
\hline TABLO 2 & Say1 & Oran $(\%)$ \\
\hline Tamamen Katıliyorum & $\mathbf{1 9 3}$ & $\mathbf{7 7 , 2}$ \\
\hline Kısmen Katıllyorum & $\mathbf{3 4}$ & $\mathbf{1 3 , 6}$ \\
\hline Kararsızım/Bilmiyorum & $\mathbf{9}$ & $\mathbf{3 , 6}$ \\
\hline Çok Az Katıllyorum & $\mathbf{6}$ & $\mathbf{2 , 4}$ \\
\hline Hiç Katılmıyorum & $\mathbf{8}$ & $\mathbf{3 , 2}$ \\
\hline Toplam & $\mathbf{2 5 0}$ & $\mathbf{1 0 0}$ \\
\hline
\end{tabular}


Tablo 3: Hekimimin Vermiş Olduğu Güvenden Memnunum

\begin{tabular}{|l|l|l|}
\hline TABLO 3 & Sayı & Oran(\%) \\
\hline Tamamen Katıllyorum & 209 & 83,6 \\
\hline Kısmen Katıllyorum & 25 & 10 \\
\hline Kararsızım/Bilmiyorum & 8 & 3,2 \\
\hline Çok Az Katıllyorum & 3 & 1,2 \\
\hline Hiç Katılmıyorum & 5 & 2 \\
\hline Toplam & 250 & 100 \\
\hline
\end{tabular}

Tablo 4: Diş Çürüğü Tedavisinde Kullanılan Malzemelerin Kalitesinden Memnunum

\begin{tabular}{|l|l|l|}
\hline TABLO 4 & Say1 & Oran (\%) \\
\hline Tamamen Katıllyorum & $\mathbf{2 2 1}$ & $\mathbf{8 8 , 4}$ \\
\hline Kısmen Katıllyorum & $\mathbf{1 2}$ & $\mathbf{4 , 8}$ \\
\hline Kararsızım/Bilmiyorum & $\mathbf{4}$ & $\mathbf{1 , 6}$ \\
\hline Çok Az Katıllyorum & $\mathbf{5}$ & $\mathbf{2}$ \\
\hline Hiç Katılmıyorum & $\mathbf{8}$ & $\mathbf{3 , 2}$ \\
\hline Toplam & $\mathbf{2 5 0}$ & $\mathbf{1 0 0}$ \\
\hline
\end{tabular}

Tablo 5: Koruyucu Hekimlik Uygulamalarının Tedavide Önemli Olduğuna İnaniyorum

\begin{tabular}{|l|l|l|}
\hline TABLO 5 & Sayı & Oran(\%) \\
\hline Tamamen Katıllyorum & 128 & 51,2 \\
\hline Klsmen Katıllyorum & 73 & 29,2 \\
\hline Kararsızım/Bilmiyorum & 26 & 10,4 \\
\hline Çok Az Katıllyorum & 14 & 5,6 \\
\hline Hiç Katılmıyorum & 9 & 3,6 \\
\hline Toplam & 250 & 100 \\
\hline
\end{tabular}

Tablo 6: Yapılan Tedaviden Memnunum

\begin{tabular}{|l|l|l|l|}
\hline TABLO 6 & MEMNUN & MEMNUN DEĞİL & TOPLAM \\
\hline & 196 & 54 & 250 \\
\hline ORAN(\%) & 78,4 & 21,6 & 100 \\
\hline
\end{tabular}

Tablo 7: Tedavi Aşamasında Hastaların Memnuniyetini Etkileyen Faktörlerin Dağılımı

\begin{tabular}{|l|l|l|l|}
\hline TABLO 7 & $\begin{array}{l}\text { Rahatsız } \\
\text { etmedi }\end{array}$ & $\begin{array}{l}\text { Rahatsız } \\
\text { etti }\end{array}$ & \\
\hline Tükürük emicinin kullanımı & 96 & 154 & $\boldsymbol{P}=\mathbf{0 . 0 1 4}$ * \\
\hline Reflektör ışı̆̆ının kullanımı & 204 & 46 & $P=0.061$ \\
\hline Kliniğin ortamı & 226 & 24 & $P=0.073$ \\
\hline $\begin{array}{l}\text { Tedavi sırasında kullanılan } \\
\text { pamuk }\end{array}$ & 211 & 39 & $P=0.068$ \\
\hline Hastanın oturma pozisyonu & 142 & 108 & $\boldsymbol{P}=\mathbf{0 . 0 4 7}$ * \\
\hline Kliniğin fiziki koşulları & 219 & 31 & $P=0.075$ \\
\hline Malzeme kalitesi & 237 & 13 & $P=0.059$ \\
\hline Materyallerin temizliği & 232 & 18 & $P=0.056$ \\
\hline Tedavi sırasında hissedilen acı & 74 & 176 & $\boldsymbol{P}=\mathbf{0 . 0 0 5}$ * \\
\hline
\end{tabular}

[Anlamlı fark oluşturma sınırı $p<0.05$ olarak Kabul edilmiştir.]
Tablo 8: Katılımcıların Yaş ve Cinsiyet Dağılımı

\begin{tabular}{|l|l|l|l|}
\hline TABLO 8 & ERKEK & KADIN & YÜZDE \\
\hline 18-29 YAŞ & 15 & 51 & 26,4 \\
\hline 30-39 YAŞ & 13 & 34 & 18,8 \\
\hline 40-49 YAŞ & 23 & 52 & 30 \\
\hline 50-59 YAŞ & 17 & 45 & 24,8 \\
\hline TOPLAM & 68 & 182 & 100
\end{tabular}

\section{TARTIŞMA}

Pearl Pei Liu ve ark. yaptıkları çalışmada, hastalardaki memnuniyet derecesinin az olmasına bağlı olarak hastaların tedaviyi sürdürmek istemediği bildirilmiştir (17). Yaptığımız çalışmada 250 hastanın 196'sının aldığı tedaviden memnun olduğu gözlemlenmiştir. $\mathrm{Bu}$ hasta grubunun \% 98'inin yapılan işlem sonucunda tedaviyi sürdürmek istemesi bu konuda yapılan önceki çalışmaları desteklemektedir. Kalan \% 2'lik grubun tedaviyi sürdürmek istememesindeki en önemli faktörün tedavi sırasında hissedilen acı olduğu gözlemlenmiştir.

Dr. Adnan Haşim' in "Diş Hekimliğinde Hipnoz" konulu yazısında; bilimsel ve yasal anlamda 1958 yılından beri tıbbi amaçlarla hipnozun resmen kabul edildiği Amerika Birleşik Devletleri'nde faal 5 tıp kuruluşunun 3 tanesinin diş hekimlerine ait kuruluşlar olduğu belirtilmektedir (18). $\mathrm{Bu}$ kapsamda diş hekimliğinde acı faktörü ve hastanın bu konudaki anksiyetesi tedavilerde çok önemli bir yer etmektedir $(11,19,20)$. Bizim yaptığımız çalışmada da tedavi sırasında hissedilen acının, hasta memnuniyetini etkileyen faktörler arasında en yüksek oranda görüldüğü bulunmuştur. En belirgin memnuniyet etkenlerinden birinin tedavi sırasında hissedilen acı olarak belirlenmesinin sebebinin hastaların ağrısız tedavi beklentisi ve tedavi sırasında hissedilen acıdan kaynaklı oluşabilecek durumlar karşısında tedavi öncesinde önyargıları olduğu düşünülmüştür. Özellikle anestezi yaparken hekimin çevre yumuşak dokulara fazla baskı uygulamasının buna sebep olabileceği düşünülmüştür. Bir diğer faktör olarak tedavi sırasında dişteki dentin dokusunda yüksek hızlı döner aletlerin kullanılması, hassasiyet hissine bağl1 hastada rahatsızlık hissine sebep olabilmektedir $(21,22)$. Kullanılan frez takımının eskimesine bağlı olarak kesme fonksiyonlarının azalması ve dişlere gereğinden fazla basınç uygulanması da hastada rahatsızlık ve acı hissi olarak karşımıza çıkan faktörler olarak gözlemlenebilmektedir. Hekimin hastayla tedavi sırasında kurduğu iletişimin hastada hissedilen acının derecesini azaltmada etkili bir araç olduğu görülmüştür $(23,24)$. Tedavi sırasında hasta ile 
konuşmanın hasta üzerinde önemli derecede olumlu etki oluşturduğu gözlemlenmiştir.

Yapılan birçok çalışma kadın hastaların diş kliniğine daha çok başvurduklarını göstermiştir. Buna bir örnek olarak; Serpil Karaoğlanoğlu ve ark. yaptı̆̆ "Diş Fırçalama ve Sigara İçme Alışkanlığının DMFT Oranına Etkisinin Demografik Verilere Göre Değerlendirilmesi” konulu yaptıkları çalışmada Restoratif Diş Tedavisi Kliniğì'ne başvuran 440 hastanın 251'inin kadın hasta olduğu tespit edilmiştir (25). Bizim yaptığımız çalışmada da 250 hastanın 182'si kadın hasta olduğu görülmüştür. Bu veriler bize, kadın hastaların erkek hastalara göre ağız sağlığına daha fazla dikkat ettiklerini ortaya çıkarmıştır. Bu bağlamda erkek hastalara ağız diş sağlığına yönelik bilinç düzeyinin arttırılmasına yönelik çalışmalar yapılabilir.

\section{SONUÇ}

Restoratif tedavi sırasında kullanılan tükürük emicinin çevre yumuşak dokulara olan baskısı ve dentin hassasiyetine sebep olması, hasta pozisyonunun ideal ergonomik konumda ayarlanamaması ve tedavi esnasında oluşan ağrı hissi hasta memnuniyetinin derecesinin düşük olmasına sebep olmaktadır. Bu da hastaların bir sonraki seanslara gelmemesine ve hekim ile ilişkilerini kesmelerine sebep olabilmektedir. Bunun sonucu olarak basit tedavi prosedürleri ile çözülebilecek olan işlemler hastalığın ilerlemesine bağlı olarak komplike hale gelmekte ve bu da hem hastayı hem de ülke ekonomisini zarara uğratmaktadır.

\section{KAYNAKLAR}

1. Kabirzadeh Azar, Benjamin Mohseni Saravi Türkiye Klinikleri, J Med Ethics, 13:199-202, 2005.

2. Aşsı T, Yalçın N. Hemşire-Hasta etkileşimi. İstanbul Üniversitesi Florence Nightingale Hemşirelik Dergisi, 19: 54-59, 2011.

3. Eroğluer Kemal, Hizmet Kalitesi Algısının Kurumsal İmaja Etkisi Üzerine Hizmet Sektöründe Bir Araştırma.Anadolu Üniverstesi Sosyal Bilimler Dergisi, S.14(1):199-219, 2011.

4. Kömürcü N. , Sağlık Hizmetlerinde Kalite, Marmara Üniversitesi , Doktora Tezi , 2006.

5. Caldwell, C. Sağlık Kuruluşlarında Stratejik Yönetim, Sistem Yayıncil1k, Cilt 23, Say1 2 61-85, İstanbul (2010).

6. Selver Suna BAŞAK, Diş Hekimlerini Etkileyebilecek Fiziksel Risk Etmenleri, Gümüşhane Üniversitesi Sağlık Bilimleri Dergisi , GÜSBD 7(1): 184-192, 2018.

7. Ayer WA, Domato PK, Gale EN, Joy ED, Melamed BG. Overcoming dental fear: strategies for its prevention and management. J Am Dent Assoc 107: 18-27, 1983.
8. Freeman RE. Dental satisfaction: A multifactorial aetilogy. Br Dent J 159: 406-408, 1985.

9. Öz F. Sağlık Alanında Temel Kavramlar, 2. Baskı. Ankara, Mattek Matbaacilik, 2015.

10. Başak S. S., Işık E. Bir Ağız Diş Sağlığı Merkezinde Çalışan Personelin Memnuniyet Düzeylerinin Belirlenmesi. 1st International Congress on Vacational and Technical Sciences - (UMTEB), Batumi, Georgia 212 - 225, 2017.

11. Ramos-Gomez F, Crystal YO, $\mathrm{Ng} \mathrm{MW}$, Tinanoff $\mathrm{N}$, Featherstone JD. Caries risk assessment, prevention, and management in pediatric dental care. Gen Dent 58(6): 505$17,2010$.

12. Stouthard MEA, Hartman CA, Hoogstraten J. Development of a Dutch version of the dental visit satisfaction scale. Community Dent Oral Epidemiol. 20:351-353, 1992.

13. Kavak B., Soğanc1, E. ve Eryigit, C., Servqual İle 'Beklenti'nin Ölçümüne Yönelik Bir Kritik. Pazarlama ve Pazarlama Araştırmaları Dergisi, 12:81-98, 2013.

14. Hakeberg M, Cunha L. Dental anxiety and pain related to dental hygienist treatment. Acta Odontol Scand 66: 374-379, 2008.

15. Mok E, Wong K. Effects of music on patients anxiety. AORN J 1: 1-13, 2003.

16. Rolander, B. Work conditions, musculoskeletal disorders and productivity of dentists in public dental care in Sweden. Linköping, Sweden, 2010.

17. Liu P. P, Wong M. C. M, Luo J. Y. N. Patients satisfaction with dental care: a qualitative study to develop a satisfaction instrument 10.1186/s12903.018.0477-7, 2018.

18. Adnan H: Diş Hekimliğinde Hipnoz. www.e-psikiyatri.com/ dis-hekimliginde-hipnoz, 2010.

19. Ay S, Özdemir D, Öztürk M, Polat S. An assessment of dental anxiety in oral surgery patients. Gülhane Tıp Dergisi 44:395-398, 2002.

20. Corah NL, O'Shea RM, Bissell GD, Thines TJ, Mendola P. The dentist-patient relationship: Perceived dentist behaviors that reduce patient anxiety and increase satisfaction. J Am Dent Assoc 116: 73-76, 1988.

21. Koçanalı B, Topaloğlu Ak A, Çoğulu D. [Evaluation of the dental caries risk factors in children]. The Journal of Pediatric Research 1(2):76-9, 2014.

22. Şenel, B. Diş hekimleri için risk taşıyan hastalıklar ve diş hekimlerinin mesleki rahatsızlıkları. Gülhane Tıp Dergisi, 204-212, 2007.

23. Mickenautsch S, Frencken JE, Van't HM. Atraumatic restorative treatment and dental anxiety in outpatients attending public oral health clinics in South Africa. J Public Health Dent 67: 179-184, 2007.

24. Yalçın Ünlüyol A, Kocabalkan E, Diş Tedavisi Öncesi Endişenin Hastanın Tedaviye Bakış Açısına Etkisi , GÜ Diş Hek Fak Derg 27(3): 167-174, 2010.

25. Karaoğlanoğlu, S., Aydin, N., Oktay, E. A., Duymuş, Z. Y., Şahin, A., \& Topçu, F. T. (2018). Diş Fırçalama ve Sigara İçme Alışkanlığının DMFT Oranına Etkisinin. Turkiye Klinikleri. Dishekimligi Bilimleri Dergisi, 24(2), 84-92. 